Disponível em

http://www.anpad.org.br/rac

RAC, Rio de Janeiro, v. 19, $3^{\text {a }}$ Edição Especial, art. 3, pp. 288-304, Outubro 2015 http://dx.doi.org/10.1590/1982-7849rac20151635

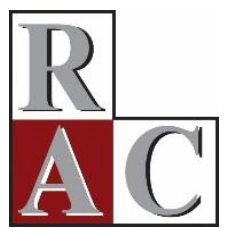

\title{
Diferentes Vínculos Indivíduo-Organização: Explorando Seus Significados entre Gestores
}

Different Individual-Organization Attachments: Exploring Their Meanings between Managers

Ana Paula Moreno Pinho Universidade Federal da Bahia - UFBA

Antonio Virgilio Bittencourt Bastos Universidade Federal da Bahia - UFBA

Diva Ester Okazaki Rowe Universidade Federal da Bahia - UFBA

Artigo recebido em 06.09.2013. Última versão recebida em 09.08.2014. Aprovado em 21.08.2014. Publicado online em 21.08.2015. 


\title{
Resumo
}

Este trabalho investigou o Comprometimento Organizacional nas bases afetiva, normativa e instrumental, de acordo com o modelo de Meyer e Allen (1991), e mais dois vínculos - Entrincheiramento e Consentimento Organizacionais. O objetivo foi analisar os significados atribuídos por gestores a esses três vínculos, explorando seus elementos distintivos. A pesquisa foi conduzida pelo método qualitativo, através de entrevistas semiestruturadas com 20 gestores. O roteiro investigava os dados pessoais e o conceito atribuído a cada um dos vínculos. Para isso, utilizou-se, como recurso, a apresentação de fichas escritas com noções sobre cada construto. Os dados foram analisados pela análise de conteúdo. Os resultados apontaram que comprometimento refere-se a aspectos positivos, às noções de envolvimento e motivação. O entrincheiramento foi relacionado ao medo de mudar de organização para não arriscar a estabilidade já adquirida. Demonstrou, ainda, ser um vínculo instrumental que aprisiona o sujeito, levando-o ao desenvolvimento de uma relação de dependência e acomodação. O consentir indicou submissão às relações de poder e autoridade, insatisfação com o trabalho e a organização. Concluiu-se que os três vínculos se diferenciam conceitualmente e indicam influenciar distintamente a relação entre indivíduo e organização.

Palavras-chave: vínculos organizacionais; comprometimento organizacional; entrincheiramento; consentimento organizacional; análise conceitual.

\begin{abstract}
This work investigated Organizational Commitment based on the three component model - affective, normative and continuance - introduced by Meyer and Allen (1991) and two constructs - Organizational Entrenchment and Consent. The objective was analysis of the meaning attributed by managers to three links, exploring their distinct elements. The research was carried out through the use of qualitative analysis of interviews with 20 managers. The interview script investigated personal data and the concepts attributed to each link. Data was submitted to content analysis. Results highlighted that managers have very different conceptual structures for the three constructs. Commitment was considered a positive tie, indicating engagement and motivation. In a different way, entrenchment was related to fear of changing organizations, in that changing jobs risks existing stability. Entrenchment turned out to be an instrumental tie that imprisons the subject and leads to development of a relationship of dependency and accommodation. Consent fit better into the idea of submission to power and authority relationships, and being unsatisfied with work and the organization. In conclusion, the three links are different in conceptual terms and indicate distinctive influence on relationships between individuals and organizations.
\end{abstract}

Key words: organizational attachments; organizational commitment; entrenchment; organizational consent; conceptual analysis. 


\section{Introdução}

Há, no campo do Comportamento Organizacional, uma forte tradição de estudos voltados para os vínculos que o trabalhador desenvolve com várias facetas do mundo do trabalho. Dentre os vínculos com a organização apontados na literatura, destaca-se o Comprometimento Organizacional. Questões conceituais e de mensuração são debatidas e, apesar da relativamente longa trajetória de pesquisa, ainda são atuais os desafios para os pesquisadores da área.

Embora não haja uma definição única para o comprometimento organizacional, os diferentes conceitos utilizados trazem como ponto em comum que se trata de um estado psicológico que caracteriza a relação do indivíduo com a organização. Essa definição geral não elimina a diversidade com que tal estado psicológico é conceituado, o que faz com que a área de pesquisa delimitada tenha como traço dominante problemas conceituais e limites pouco claros entre as diferentes bases do comprometimento.

O modelo multidimensional de Comprometimento incorpora várias bases, o que permite enquadrar diversas relações como sendo uma relação de comprometimento. No entanto, o vínculo do trabalhador, quando mais fortemente caracterizado por um sentimento de lealdade, de obediência, de adesão às normas e procedimentos organizacionais, pode constituir-se menos em comprometimento e mais em obediência ou Consentimento Organizacional, como proposto por Silva e Bastos (2010). A literatura sociológica oferece suporte à noção de que esse vínculo é, de fato, uma relação de subordinação a uma figura de autoridade relacionada ao contexto organizacional. A extensão desse conceito coloca-se como um dos problemas estudados na presente investigação, o que conduz à necessidade de caracterização do significado de estar comprometido e o de consentir ou ser obediente no local de trabalho.

Da mesma forma, acumularam-se evidências empíricas de que o comprometimento de continuação, uma das três bases do modelo de Meyer e Allen (1991), apresenta um padrão oposto no que se refere às relações com o desempenho e com outras variáveis quando comparado ao que é encontrado com as bases afetiva e normativa. O comprometimento de continuação apresenta correlações negativas com a cidadania organizacional (Cunha, Rego, Cunha, \& Cabral-Cardoso, 2004), ao contrário das dimensões Afetiva e Normativa. Adicionalmente, o comportamento de negligência se configura como a única correlação positiva desse vínculo instrumental. Neste sentido, Rodrigues e Bastos (2011) propuseram o construto Entrincheiramento Organizacional, embasados na compreensão de que a permanência na organização pelos altos custos associados à saída do trabalhador, aproxima-se mais da noção de entrincheiramento (conceito já existente no campo de estudo das carreiras) do que do comprometimento.

O presente trabalho foi desenvolvido a partir desta discussão que problematiza os limites ou a extensão do construto Comprometimento Organizacional em suas dimensões afetiva, normativa e de continuação, e aponta o surgimento de novos construtos - Consentimento e Entrincheiramento Organizacionais. Parte-se, portanto, da necessidade de se compreender como esses diferentes vínculos desenvolvidos pelos atores organizacionais se diferenciam entre si.

O objetivo central é o de mapear os significados associados aos conceitos de Comprometimento, Entrincheiramento e Consentimento entre gestores que atuam em diferentes contextos organizacionais. Explora-se, assim, a estrutura conceitual que deve guiar o gestor na sua relação com sua equipe de trabalho, ao mesmo tempo em que são reunidas evidências adicionais para revisar o modelo tridimensional de comprometimento organizacional. 


\section{Análise Conceitual sobre Comprometimento Organizacional}

Klein, Molloy e Cooper (2009) dividem as concepções acerca do comprometimento em três grandes categorias: aquelas que adotam noções independentes, as que estão relacionadas aos antecedentes do construto e as que se referem aos consequentes do construto.

Algumas concepções conceituam comprometimento como uma atitude, uma força ou, ainda, um vínculo. Na perspectiva das atitudes, estão os trabalhos de Mowday, Porter e Steers (1982), que usam o termo Comprometimento atitudinal; Chusmir (1982), que descreve o Comprometimento no trabalho como uma orientação frente a esse foco; e Blau (1985), que define o construto, adaptado ao estudo da carreira, como uma atitude frente a uma vocação ou ação profissional.

Allen e Meyer (1996) ressaltam que definir Comprometimento como uma atitude se torna problemático devido às superações na literatura quanto à definição tripartite (afeto, cognição e comportamento) do conceito de atitudes. Na visão de Ajzen (2001), há um consenso geral de que uma atitude representa uma avaliação sumária do objeto capturado psicologicamente e dimensões são atribuídas no sentido bom ou ruim, prejudicial ou benéfico, prazeroso ou não prazeroso e, ainda, agradável ou não agradável. Segundo Klein et al. (2009), essa visão acerca das atitudes dificulta a compreensão do construto, visto que ser comprometido a um objetivo ou alvo se diferencia de fazer um julgamento favorável ou desfavorável. Portanto, para alguns autores, essa perspectiva atitudinal não descreve apropriadamente o conceito de comprometimento.

Há, também, concepções que consideram esse construto uma mistura com outros aspectos, incluise, aqui, a noção de Comprometimento como uma força e como um vínculo. Analisando como uma força, considera-se que os antecedentes do construto criam pressões que são vivenciadas como uma atração mental que liga o indivíduo ao objetivo almejado. Scholl (1981), Meyer e Herscovitch (2001) adotam essa perspectiva. Mais recentemente, Meyer (2009) explica que Comprometimento é algo que reside no indivíduo e refere-se a uma força interna que liga o mesmo a um objetivo (social ou não social) ou, ainda, a um curso de ação relevante para atingir esse objetivo.

O autor analisa, em trabalhos anteriores (Meyer \& Allen, 1997), o quanto esse tipo de vínculo pode ser influenciado por diversos fatores, e inclui aqueles que são intrínsecos, como personalidade e valores, e extrínsecos, a exemplo das normas e experiências de trabalho. Essa força interna é vivida como uma característica mental que determina a maneira em que o indivíduo irá interpretar a situação e responder a esta. A esse conjunto de características mentais, Meyer (2009) denomina de mindset, que pode se referir a um desejo (comprometimento afetivo), obrigação (comprometimento normativo) e a custos percebidos (comprometimento de continuação) ou, ainda, algumas combinações entre esses tipos de mindsets. Não se inclui, portanto, a possibilidade de influências inconscientes nessa força mental. A natureza desse conjunto de características mentais tem implicações importantes para a qualidade do relacionamento com o objetivo ou o comportamento perseguido.

Outra noção independente é a de vínculo, que, ao se analisar o Comprometimento por essa perspectiva, identifica-se como um estado psicológico que é representado fortemente através de um apego ao alvo. Os trabalhos de Buchanan (1974), O'Reilly e Chatman (1986) e Mathieu e Zajac (1990) representam essa noção. Segundo O'Reilly e Chatman (1986), comprometimento pode ser definido como "sentimento de apego psicológico do indivíduo em prol da organização e isso irá refletir no grau em que o indivíduo internaliza ou adota características da organização" (p. 493).

Concepções que trazem a noção de antecedentes incluem Comprometimento como troca ou investimentos, identificação e objetivo ou alvo congruente. A natureza do investimento ou troca pode ser econômica, comportamental, social ou uma combinação entre elas. Exemplos dessa concepção são de Becker (1960, p. 32) "Comprometimento ocorre quando uma pessoa, ao estabelecer uma relação de troca, associa o interesse com uma linha consistente de atividade", e Hrebiniak e Alluto (1972, p. 271) "Comprometimento é um fenômeno estrutural que ocorre como um resultado de transações entre indivíduo-organização e alterações nas trocas ou investimentos ao longo do tempo". 
E, ainda, há concepções de Comprometimento que abordam o fenômeno como um resultado das noções de motivação e continuação. Para Klein et al. (2009), definir comprometimento por esses termos indica uma mistura com elementos que devem predizer o Comprometimento. Nesse sentido, Wiener (1982) define o construto como "a totalidade das pressões normativas para agir no mesmo caminho dos objetivos e interesses organizacionais" (p. 421).

Esse cenário mostra que existe uma série de definições e diferentes modelos teóricos que são resultantes dessas distintas noções. Observa-se que há sobreposições entre algumas categorias que definem o construto, principalmente as que envolvem a noção de construto como uma atitude, identificação e congruência. Nota-se que há pouco consenso entre os autores acerca da definição que melhor aborda o tema. Isso promove a confusão conceitual, um problema que tem sido regularmente encontrado na literatura. Para o desenvolvimento da presente investigação, optou-se por trabalhar com a concepção de comprometimento organizacional, de acordo com o modelo tridimensional defendido por Meyer e Allen (1991) e atualizada em 2009.

\section{Entrincheiramento organizacional}

O construto Entrincheiramento é tratado, na literatura, a partir das pesquisas realizadas no campo de estudos das carreiras por Carson e Bedeian (1994) e Carson, Carson e Bedeian (1995). Os autores introduziram o conceito de Entrincheiramento para diferenciar de Comprometimento com a carreira, campo de investigação ao qual o modelo tridimensional de Meyer e Allen (1991) foi estendido. Para esses autores, entrincheiramento na carreira diz respeito à decisão de continuar na mesma linha de ação profissional por falta de opções, pela sensação de perda dos investimentos já realizados, ou pela percepção de um preço emocional a pagar muito alto para mudar. A mesma base teórica que é utilizada para tratar do Comprometimento de Continuação - troca instrumental introduzida por Becker (1960) foi adotada para fundamentar o sentido de trocas materiais embutido no construto Entrincheiramento.

Recentemente, Rodrigues e Bastos (2011) propuseram a adaptação do Entrincheiramento para o contexto organizacional, o que os autores chamam de Entrincheiramento Organizacional. Mediante uma proposta preliminar de medida para esse construto, os mesmos definiram três dimensões para a sua composição - Ajustamento à Posição Social, Arranjos Burocráticos Impessoais e Limitações de Alternativas. O instrumento proposto foi aprimorado por Rodrigues e Bastos (2011), que mantiveram as mesmas dimensões para o construto. A utilização da escala preliminar ocorreu em uma investigação realizada por Pinho e Bastos (2014), ao analisarem empiricamente esse novo vínculo em uma amostra de 268 trabalhadores.

A essência do vínculo Entrincheiramento Organizacional envolve a noção de o indivíduo estar preso numa organização por não conseguir visualizar uma alternativa que o sustente de acordo com suas necessidades e expectativas. Rodrigues e Bastos (2011) acrescentam que não é possível falar de uma permanência espontânea do trabalhador entrincheirado, mas sim em decorrência da sua necessidade.

\section{Consentimento organizacional}

O construto Consentimento Organizacional encontra na literatura sociológica um dos seus pilares teóricos, em que o vínculo entre indivíduo e organização é visto a partir de uma perspectiva que, descartando elementos afetivos e psicológicos, enfatiza as relações de controle e autoridade que induzem o trabalhador a obedecer ou cumprir o papel de subordinado dele esperado. A origem do termo submissão situa-se nessa perspectiva, mais especificamente nos estudos de Weber sobre a autoridade. A partir desse referencial, é possível articular que o indivíduo já tem internalizado um papel de submissão ao patrão, à chefia, o que, para empregados de menor escolaridade, com níveis mais simples de ocupação, aliados a poucas oportunidades de emprego, favorece realmente uma conduta subserviente. De acordo com o sistema de autoridade preconizado por Weber (1971), consentimento ocorre devido à existência das normas e da sua eficiência no nível formal do grupo. 
Esse novo construto tem sido estudado muito recentemente por Silva e Bastos (2010) através da proposta de medida para esse construto. O conceito de Consentimento Organizacional que norteia a presente pesquisa baseia-se na definição proposta pelos autores, que considera o construto como bidimensional - Obediência Cega e Aceitação Íntima.

A dimensão Obediência Cega significa cumprimento automático da ordem, sem envolver avaliação ou julgamento a respeito desta. $\mathrm{O}$ trabalhador se comporta de acordo com as ordens estabelecidas pelo seu superior hierárquico e não se considera responsável por nenhuma consequência, principalmente negativa, que possa advir de suas ações. Já a dimensão Aceitação Íntima significa cumprimento das normas e regras estabelecidas em função de uma concordância autêntica com as mesmas. Há, portanto, similaridade entre as visões do indivíduo e da organização, o que o levaria a uma identificação com as regras, os procedimentos e os valores que embasam as decisões dos gestores.

\section{Método}

No campo das Ciências Sociais Aplicadas, há fenômenos complexos que favorecem a aplicação da abordagem qualitativa, tanto no que diz respeito ao tratamento contextual do fenômeno quanto no que tange a sua operacionalização. De acordo com Vieira e Zouain (2005), a pesquisa qualitativa busca apresentar explicações teóricas e pretende se constituir como um estudo intensivo e detalhado dos fenômenos. Visa, também, atender a indicadores qualitativos que se referem aos dados psicológicos que não são facilmente articulados.

A natureza do presente trabalho, voltado para explorar e mapear o conjunto de significados que podem diferenciar ou aproximar estes três tipos de vínculos organizacionais, indica a pertinência de se utilizar uma estratégia metodológica qualitativa, voltada para apreender o discurso dos participantes, articulando os resultados à base teórica já disponível na literatura.

\section{Instrumento de coleta de dados}

Para o desenvolvimento deste estudo, as informações foram colhidas através de um roteiro semiestruturado que investigava, dentre outras questões, as informações referentes ao tipo de vínculo desenvolvido pelo trabalhador perante a organização empregadora, de acordo com a percepção dos respectivos gestores. O roteiro de entrevista iniciava com aspectos relacionados aos Dados Pessoais, como sexo, idade, escolaridade, estado civil, profissão, nível de renda, número de dependentes, ocupação, tempo de serviço no cargo e na organização.

O segundo momento da entrevista constituiu-se da apresentação de 30 fichas com frases escritas que representavam ideias centrais acerca de cada um dos construtos, sendo 10 fichas para cada um Comprometimento Organizacional Afetivo, Consentimento Organizacional e Entrincheiramento Organizacional. Em função da quantidade de fichas que seriam manipuladas pelo entrevistado, optouse por concentrar mais o sentido do Comprometimento pela dimensão afetiva, e explorar o sentido proposto pelos outros vínculos, isto é, as noções de obediência e trocas materiais em função da sobrevivência.

Após a apresentação das 30 fichas, os entrevistados eram levados a escolher, dentre aquelas, as dez que representassem um trabalhador comprometido, de acordo com o seu próprio conceito e, em seguida, eram questionados a agrupar as outras fichas conforme o próprio entendimento deles, e depois justificavam aquela seleção. Dando continuidade, a entrevistadora separou as 30 fichas em três colunas, seguindo a seleção que o próprio entrevistado tinha feito na etapa anterior. Ressalta-se que o gestor não foi informado sobre a definição e a denominação teórica de cada construto, a fim de não causar interferências nas suas respostas. Cada sujeito expressou suas próprias denominações, revelando suas convicções e significados. Após a apresentação das colunas de frases, o entrevistado foi questionado sobre o nome que eles dariam a um trabalhador que apresentasse aquelas características: Como você 
chamaria trabalhadores que apresentam estas características? Como se chamaria um trabalhador que pensa e age assim?

\section{Procedimentos para coleta, tratamento e análise dos resultados}

$\mathrm{O}$ agendamento das entrevistas foi feito através do setor de RH de cada organização. Foram realizadas no próprio local de trabalho, durante a jornada e de acordo com a conveniência de cada gestor. As entrevistas foram gravadas em aparelho $\mathrm{Mp} 3$, sendo que apenas uma entrevista não foi gravada em função da não autorização do próprio entrevistado, o que levou os pesquisadores a fazerem anotações durante a emissão das respostas.

Os relatos foram analisados através da técnica análise de conteúdo. Essa técnica tem como objetivo o estudo e a análise da comunicação de maneira objetiva, sistemática e quantitativa, afirma Martins (2006). Buscam-se, a partir dos discursos dos sujeitos participantes da pesquisa, as inferências confiáveis de informações a respeito das questões que norteiam o problema da pesquisa. $\mathrm{O}$ autor ressalta que é enfatizada a essência de um contexto nos detalhes das informações disponíveis, focalizando não apenas o texto, mas, principalmente, a forma como a palavra é usada. Portanto, a análise de conteúdo não se restringe à descrição dos conteúdos revelados na entrevista, mas atua sobre o todo da comunicação, buscando entendimento acerca das causas e dos antecedentes da mensagem, bem como sobre os efeitos relatados pelos entrevistados.

Os autores Dellagnelo e Silva (2005) e Martins (2006) apresentam, de maneira semelhante, três etapas ou momentos da análise de conteúdo. Inicialmente, ocorre a pré-análise, que corresponde à coleta, organização do material e definição dos procedimentos a serem seguidos. Em seguida, acontece a exploração do material, envolvendo a descrição analítica, com implementação dos procedimentos: contagem das palavras ou das outras unidades de análise, levantamento de categorias já testadas ou construção de categorias a partir das frequências e dos significados comuns das unidades de análises. A categorização inclui o inventário das unidades de análises de palavras, temas, frases e a classificação das unidades comuns, revelando as categorias. A terceira etapa constitui-se do tratamento dos dados, que envolve a geração de inferências sobre o texto, de maneira geral, e as interpretações.

\section{Características dos sujeitos participantes}

Participaram da pesquisa três organizações, sendo duas do âmbito público e uma, do privado. As organizações públicas atuam no setor de tecnologia em nível federal e municipal, e a privada atua no setor de comércio e varejo. As três organizações encontram-se situadas na cidade de Salvador, Estado da Bahia. A escolha das organizações participantes e dos respectivos gestores aconteceu por conveniência dos pesquisadores, isto é, em função de contatos pessoais que promoveram o seu acesso ao setor de Recursos Humanos e à aceitação da realização da pesquisa. Após o contato com esse setor, os pesquisadores foram encaminhados aos gestores de diferentes setores internos das organizações para realização das entrevistas e para receberam o consentimento dos mesmos para a participação.

Os dados que caracterizam os gestores que participaram da pesquisa encontram-se organizados na Tabela 1, a seguir. 
Tabela 1

Características dos Gestores Participantes da Pesquisa

\begin{tabular}{|c|c|c|c|}
\hline SUJEITOS (20) & ORGAN. FEDERAL (7) & ORGAN. MUNICIPAL (8) & ORGAN. PRIVADA (5) \\
\hline SEXO & 5 homens e 2 mulheres & 6 homens e 2 mulheres & 4 homens e 1 mulher \\
\hline IDADE & 33 e 53 anos & 35 a 51 anos & 25 e 51 anos \\
\hline ESCOLARIDADE & $\begin{array}{l}1 \text { mestre, } 3 \text { especialistas, } 1 \\
\text { cursando especialização, } 1 \\
\text { superior completo e } 1 \\
\text { superior incompleto }\end{array}$ & $\begin{array}{l}5 \text { especialistas, } 2 \\
\text { mestrandos, } 1 \text { superior } \\
\text { completo }\end{array}$ & $\begin{array}{l}1 \text { superior incompleto, } 4 \\
\text { ensino médio completo }\end{array}$ \\
\hline ESTADO CIVIL & 5 casados e 2 divorciados & 6 casados, 2 solteiros & 1 solteiro, 4 casados \\
\hline PROFISSÃO & $\begin{array}{l}3 \text { analistas de sistemas, } 2 \\
\text { administradores, } 1 \text { analista } \\
\text { de informática e } 1 \text { pedagogo }\end{array}$ & $\begin{array}{l}5 \text { analistas de sistemas; } 2 \\
\text { administradores; } 1 \text { contador }\end{array}$ & Comerciários (5) \\
\hline RENDA & 10 e 20 salários mínimos & 10 a 15 salários mínimos & 3 a 10 salários mínimos \\
\hline
\end{tabular}

Os participantes da presente pesquisa revelaram diferenças mais significativas em relação à escolaridade, aos rendimentos e à faixa etária. Em geral, os gestores das organizações públicas têm maior nível de escolaridade, pois, na sua maioria, são pós-graduados, enquanto que, na empresa privada, apenas um deles encontra-se cursando o nível superior e os demais têm somente o ensino médio completo. Esse dado se reflete na identificação das profissões desses atores organizacionais, isto é, para aqueles que se encontram na organização privada, não foi identificada nenhuma formação acadêmica que garanta uma profissão a esses sujeitos, todos se enquadraram na categoria comerciários. Já os que atuam na atividade de gestão nas organizações públicas se identificaram pela profissão adquirida através da formação acadêmica.

\section{Resultados e Discussão}

As respostas emitidas expressavam o conteúdo que cada entrevistado tinha em mente a respeito daquele tipo de vínculo, pois os mesmos não foram informados sobre a denominação existente para cada construto na literatura. Os resultados serão apresentados considerando-se os procedimentos utilizados para explorar o conceito revelado por cada gestor. Os recursos explorados para apresentação e discussão dos resultados foram articulados para delimitar o conceito central de Comprometimento, na visão dos gestores, e identificar se, na estrutura conceitual acerca desse construto, há indicadores que eliminam noções que possam estar associadas ao estar entrincheirado ou ao ser obediente. Portanto, a análise das ideias e das concepções reveladas pelos gestores a respeito desses vínculos explora os elementos distintivos que podem ser identificados entre os mesmos. Ressalta-se, aqui, que o objetivo deste trabalho foi o de analisar o fenômeno vínculo organizacional e não exatamente o de fazer a contextualização dos mesmos nos contextos público e privado. Parte-se do entendimento de que qualquer trabalhador que mantém um vínculo empregatício, seja em um contexto público ou em um privado, poderá desenvolver um vínculo psicológico que o une à organização. Além disso, a escolha dos entrevistados desta pesquisa não ocorreu com o objetivo de abordar as questões de liderança bem como as especificidades do segmento produtivo, mas sim o de buscar elementos que tratem da possibilidade de distinção entre os vínculos comprometimento, consentimento e entrincheiramento, independente do tipo de organização ao qual o trabalhador esteja inserido. 


\section{Aprofundando o conceito de trabalhador comprometido para gestores das três organizações}

Para delimitar o conceito de trabalhador comprometido, apresenta-se, de início o conjunto de conteúdos que foram escolhidos pelos gestores dentre as trinta fichas que lhes foram apresentadas. Como se observa na Tabela 2, para cada ideia selecionada, registrou-se a frequência com que a mesma foi escolhida. Além da frequência, foi observada a ordem de citação do conteúdo da ficha e, posteriormente, foi feito o registro. Estes procedimentos foram seguidos atendendo aos critérios defendidos por Abric (1994) nos estudos sobre representações sociais. Assim, a Tabela 2 apresenta, além desses dados, a ordenação das frases escolhidas, tanto pela frequência quanto pela evocação.

Tabela 2

Frases Selecionadas para Definir Trabalhador Comprometido

\begin{tabular}{|c|c|c|c|c|}
\hline Frases escolhidas & Frequência & $\begin{array}{l}\text { Posição pela } \\
\text { frequência }\end{array}$ & $\begin{array}{l}\text { Ordem de } \\
\text { evocação } \\
\text { (média) }\end{array}$ & $\begin{array}{l}\text { Posição pela } \\
\text { ordem de } \\
\text { evocação }\end{array}$ \\
\hline 1. Sentir orgulho em fazer parte da organização (C). & 20 & $1^{\circ}$ & 3,3 & $1^{\circ}$ \\
\hline $\begin{array}{l}\text { 3. Assumir os objetivos da organização como se } \\
\text { fossem seus (C). }\end{array}$ & 20 & $1^{\circ}$ & 4,4 & $2^{\circ}$ \\
\hline $\begin{array}{l}\text { 5. Gostar da organização pelas oportunidades que } \\
\text { tem de crescimento no trabalho (C). }\end{array}$ & 19 & $2^{\circ}$ & 4,9 & $3^{\circ}$ \\
\hline 7. Ter interesse pelo destino da organização (C). & 19 & $2^{\circ}$ & 5,1 & $5^{\circ}$ \\
\hline $\begin{array}{l}\text { 9. Considerar a organização como sendo a melhor de } \\
\text { todas para se trabalhar (C). }\end{array}$ & 18 & $3^{\circ}$ & 5,6 & $7^{\circ}$ \\
\hline 2. Identificar-se com os valores da organização (C) & 17 & $4^{\circ}$ & 4,4 & $2^{\circ}$ \\
\hline 4. Sentir a organização como se fosse sua (C). & 15 & $5^{\circ}$ & 4,4 & $2^{\circ}$ \\
\hline $\begin{array}{l}\text { 8. Sentir-se vinculado emocionalmente à organização } \\
\text { (C). }\end{array}$ & 12 & $6^{\circ}$ & 5,2 & $6^{\circ}$ \\
\hline $\begin{array}{l}\text { 6. Vivenciar os problemas da organização como se } \\
\text { fossem os seus próprios problemas (C). }\end{array}$ & 9 & $7^{\circ}$ & 5 & $4^{\circ}$ \\
\hline $\begin{array}{l}\text { 12. Aceitar normas mesmo que pense diferente da } \\
\text { empresa (Cons.). }\end{array}$ & 7 & $8^{\circ}$ & 8,3 & $10^{\circ}$ \\
\hline $\begin{array}{l}\text { 10. Sentir-se feliz por dedicar o resto da carreira a } \\
\text { esta organização (C). }\end{array}$ & 6 & $9^{\circ}$ & 7 & $8^{\circ}$ \\
\hline 11. Cumprir normas mesmo sem concordar (Cons.). & 3 & $10^{\circ}$ & 7,2 & $9^{\circ}$ \\
\hline
\end{tabular}

Nota. (C) indicador de Comprometimento e (Cons.) indicador de Consentimento.

O conceito de trabalhador comprometido expresso por esses gestores é claramente definido por ideias pertinentes aos indicadores do construto. Das dez sentenças escolhidas, no geral, oito foram retiradas do conjunto de itens que o definiam operacionalmente. Apenas duas integravam o conceito de consentimento. É importante registrar que dos 20 gestores entrevistados, a maioria daqueles conteúdos escolhidos é típica do conceito de comprometimento: sentimento de orgulho em pertencer à organização, compartilhamento de valores individuais e organizacionais, assumir os objetivos organizacionais como se fossem do próprio empregado, fortalecimento da noção de ter a organização como se pertencesse a si mesmo, bem como o gosto pelas oportunidades que tem de crescimento e o interesse pelo destino da organização. 
Outras ideias foram citadas e complementam o sentimento positivo diante da organização, caracterizando o comprometimento como um vínculo predominantemente afetivo: vivenciar os problemas da organização como se fossem do próprio empregado, sentir-se vinculado emocionalmente e considerá-la como sendo a melhor de todas para se trabalhar. Duas ideias que definem teoricamente o construto Consentimento foram citadas para definir um trabalhador comprometido, embora tenham sido vistas como menos importantes para essa definição, ou seja, ocuparam os últimos lugares em termos de posição pela ordem de evocação, nono e décimo lugares, respectivamente. Essas ideias incluíram a noção de ter que cumprir normas mesmo sem concordar (evocada por 3 gestores) e aceitar normas mesmo que pense diferente da empresa, sendo evocado por 7 gestores. Ambos os itens referem-se à dimensão Obediência Cega do construto. Vale destacar que nenhuma das frases utilizadas como descritores do construto de entrincheiramento concentrou um número de escolhas que as posicionasse entre as ideias mais definidoras de um trabalhador comprometido.

A Figura 1 apresenta os dados constantes na Tabela 2, organizando-os em três grandes áreas: as ideias que são o núcleo central (mais escolhidas e escolhidas preferencialmente); o sistema periférico, que contém conteúdos e significados que, embora tenham sido escolhidos por alguns gestores, não exerceram o mesmo nível de influência na definição desse trabalhador e, finalmente, o sistema residual, com conteúdos que foram escolhidas por poucos gestores e se posicionam entre as últimas escolhidas em termos de ordem.

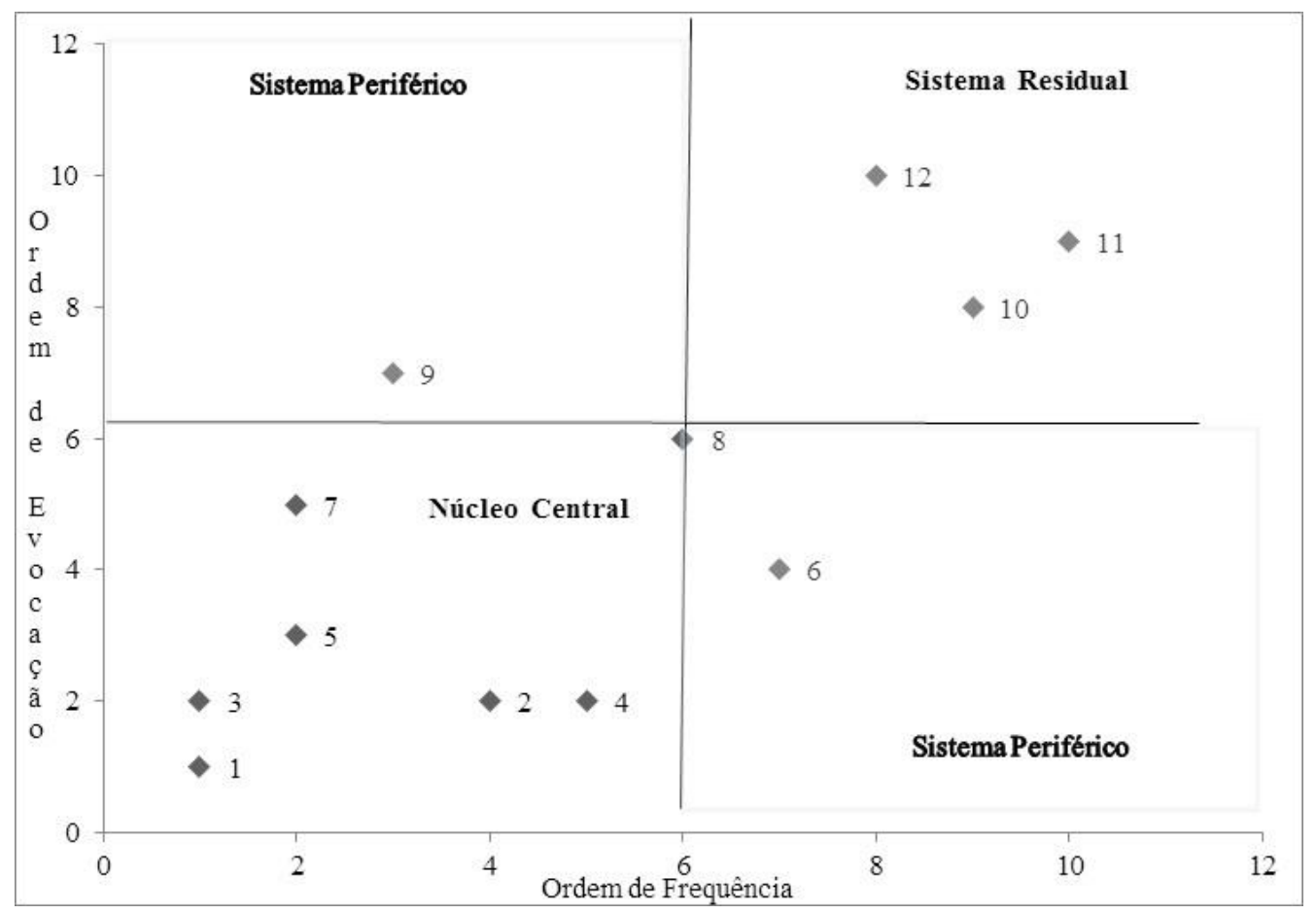

Figura 1. Conteúdos que Caracterizam um Trabalhador Comprometido

Na Figura 1, os números representam o ponto em comum entre a ordem de frequência e a ordem de evocação das fichas que foram apresentadas aos entrevistados e que representavam conteúdos referentes a cada um dos construtos investigados na pesquisa - comprometimento afetivo, consentimento e entrincheiramento. Os números, acompanhados de símbolos que representam a sua localização no gráfico, estão distribuídos em distintos quadrantes intitulados Sistema Periférico, primeiro e quarto quadrantes; Sistema Residual, segundo quadrante, e Núcleo Central, terceiro quadrante. Fonte: Adaptado de Pinho, A. P. M., \& Bastos, A. V. B. (2014). Vínculos do trabalhador com a organização: comprometimento, entrincheiramento e consentimento (p. 159). São Paulo: Hucitec Editora.

De acordo com a Figura 1, o núcleo central reuniu seis frases, sendo que cinco delas indicaram noções predominantemente afetivas, e uma que relacionou o afeto a uma noção de troca - gostar da organização pelas oportunidades que tem de crescimento no trabalho - tendo ocupado, de maneira expressiva (19 evocações), o terceiro lugar. No núcleo periférico, apareceram os conteúdos de Vivenciar os problemas da organização como se fossem os seus próprios problemas e Considerar a organização como sendo a melhor de todas para se trabalhar. A frase Sentir-se vinculado 
emocionalmente à organização, indicativa de conteúdo essencialmente afetivo localizou-se em um ponto central entre os quadrantes. Foi evocada 12 vezes e ocupou o $6^{\circ}$ lugar em termos de posição pela ordem de evocação. Já o sistema residual concentrou as duas frases do construto Consentimento Organizacional - Cumprir normas mesmo sem concordar e Aceitar normas mesmo que pense diferente da empresa - e uma frase representativa de um vínculo afetivo, Sentir-se feliz por dedicar o resto da carreira a esta organização. Parece pertinente que esta frase com conteúdo afetivo tenha se localizado na categoria residual, já que indica que o indivíduo atrela a sua carreira a uma organização, algo pouco coerente com o cenário atual do mundo do trabalho, já que é comum os trabalhadores vivenciarem vínculos pouco duradouros e muitas vezes frágeis.

A citação de itens, por parte dos gestores das organizações públicas, que se referiam ao cumprimento das normas, assumiu o sentido de regras e leis que regulam o funcionamento da organização pública e que caracterizam esse contexto devido ao sistema político burocrático no qual estão inseridas. A fala seguinte ilustra esse conteúdo:

"Por ser um órgão público, ele está limitado a cumprir principalmente leis, legislação, então, mesmo que a gente pense diferente, que podia ser mais ágil aqui ou ali, as normas e as leis nos impedem, então não é um aceitar por aceitar, aceitar sob estas condições de que existem algumas limitações, de que existe um caminho a ser seguido". (Entrevistado 1).

$\mathrm{Na}$ organização privada, o sentido atribuído foi de cumprimento das normas e obediência ao patrão em função da manutenção do próprio vínculo empregatício.

Esses resultados indicaram que o conceito de trabalhador comprometido foi constituído, nesta pesquisa, essencialmente de conteúdos que apontam um vínculo afetivo, no qual as expectativas diante da organização são valorativamente positivas e pressupõem um envolvimento construtivo. Ressalta-se que foi possível perceber no discurso algumas referências direcionadas às noções normativas e de instrumentalidade, no entanto, tais noções foram mais exploradas em relação ao sentido proposto pelos outros construtos - Entrincheiramento e Consentimento - o que permitiu a concentração do sentido de ser comprometido mais pelo aspecto afetivo.

A análise feita indica, ainda, que o conceito de comprometimento assumiu um sentido diferente do estar entrincheirado e do consentir na organização. Estar comprometido aponta identificação com a organização, desenvolvimento de afetos positivos e relação de troca que envolve a busca de oportunidades e o crescimento do indivíduo nela. Assim, o vínculo demonstra ser alimentado pelo indivíduo de maneira consciente na medida em que acredita nos valores e nos objetivos organizacionais, e percebe o próprio envolvimento, levando o mesmo a desenvolver expectativas diante da organização empregadora.

\section{Comprometimento, entrincheiramento e consentimento organizacionais: o que define tais vínculos para os gestores}

Ao se apresentar o conjunto de descritores utilizados para cada um dos três construtos, solicitouse que o entrevistado nomeasse o trabalhador com aquelas características. As respostas emitidas expressavam, portanto, o conteúdo que cada entrevistado tinha em mente a respeito daquele tipo de vínculo, já que não tinham sido informados sobre a denominação existente para cada construto na literatura.

Os nomes atribuídos pelos gestores a cada conjunto de descritores, nas três organizações, revelaram que os três construtos carregam sentidos bastante diferentes entre si e apresentam significados que indicam noções até mesmo antagônicas. Uma visão geral dessas denominações pode ser vista na Figura 2. Nesta figura, encontram-se registrados o conjunto de conteúdos nomeados pelos entrevistados, agrupados por tipo de vínculo. Registrou-se, também, o número de vezes em que uma mesma palavra foi atribuída ao conjunto de descritores, o que aparece em número entre parênteses na figura. 


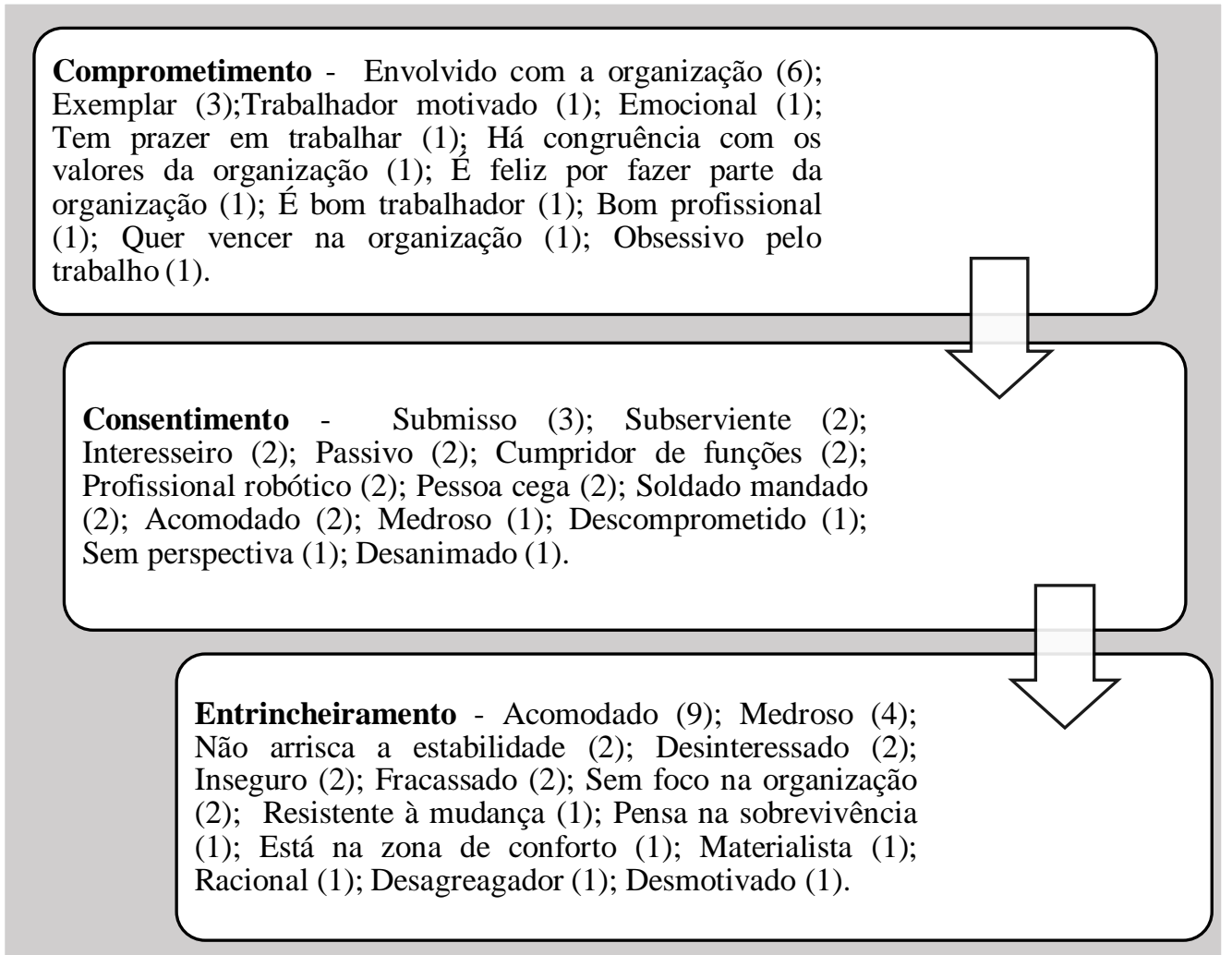

Figura 2. Denominações dos Vínculos Comprometimento, Entrincheiramento e Consentimento Organizacionais

A noção que foi revelada a respeito do comprometimento corrobora os resultados que foram encontrados na definição de um trabalhador comprometido, isto é, indicou que esse é um vínculo relacionado à motivação, ao prazer e ao envolvimento com a organização, bem como ao perfil de um trabalhador dedicado e exemplar. Nas palavras de um dos gestores da organização privada, um trabalhador comprometido "é um profissional de ponta" (Entrevistado 2).

Além de perceptível nas denominações empregadas, as justificativas deixam ainda mais explícitas que a noção atribuída a comprometimento se mostrou ligada a aspectos desejáveis tanto para o indivíduo como para a organização, evidenciando-se reciprocidade quanto ao nível e à qualidade do envolvimento entre atores e sistemas organizacionais.

Surgiu, também, no discurso, a noção de alguém sonhador e com demonstração de carga emocional como aspectos importantes para definir um trabalhador comprometido:

"Este grupo de trabalhadores está relacionado com o prazer em estar na organização, então por isso eu coloco a emoção, a decisão é baseada no emocional, ser feliz em estar naquela organização, os valores da organização têm tudo a ver com eles”. (Entrevistado 3).

Esses dados corroboram os achados de estudos brasileiros qualitativos que exploram o conceito de comprometimento a partir da ótica de diferentes atores organizacionais (Bastos, Brandão, \& Pinho, 1997; Brito \& Bastos, 2001). Os resultados desses estudos, de maneira geral, indicam como conteúdos centrais do conceito de comprometimento às noções de engajamento, dedicação à organização, zelo pelo setor em que trabalha, respeito à hierarquia, às normas e aos procedimentos organizacionais, preocupação com o crescimento da organização, cumprimento do contrato de trabalho, zelo pela imagem da organização, busca de crescimento pessoal e profissional junto à instituição. Também são citadas, nesses estudos brasileiros, ideias relativas à permanência e troca como forma de expressão desse vínculo, a exemplo do desejo de ficar na organização ou permanecer nela, apesar de outras oportunidades, e, ainda, a noção de comprometimento como uma via de mão-dupla. 
Recentemente, em um estudo qualitativo acerca dos elementos esquemáticos do conceito de trabalhador comprometido, Moscon, Bastos e Souza (2012) identificaram que o comprometimento afetivo foi considerado um vínculo que revela compromisso com a organização, o engajamento e a motivação do trabalhador. Desta forma, o comprometimento também se referiu a uma noção positiva, algo que indica identificação e apego emocional à organização para a qual trabalha.

A noção de estar entrincheirado ou consentir/ser obediente no contexto organizacional revelou sentidos opostos em relação àqueles que foram identificados para comprometimento. Foram citados os conteúdos relacionados à acomodação, à insegurança, ao medo de mudança, à luta pela sobrevivência como sendo mais representativos da noção de estar entrincheirado.

Consentir na organização indicou subserviência e submissão, falta de análise crítica, acomodação, insatisfação e realização da atividade de forma mecânica. Dois dos entrevistados associaram o consentimento a um quadro de obediência que caracteriza o trabalhador a um soldado mandado, sendo este um trabalhador que não questiona, não contribui e, ainda, não proporciona bons resultados.

Para um dos entrevistados, o entrincheiramento está relacionado muito fortemente à manutenção da própria vida, o que pode levar ao adoecimento tanto do indivíduo como da organização. A fala seguinte revela esse pensamento:

"Esse grupo racional (entrincheiramento) está muito mais pela questão da sobrevivência. Essa coisa material, esse tipo de visão, de pensamento, faz com que as pessoas se acomodem, virem uma organização acomodada, e uma empresa que fica durante muito tempo estagnada está propensa a ser extinta e possivelmente terá uma sobrevida maior do que a do outro grupo, a do irracional (grupo do consentimento), diferente do grupo emocional (comprometimento), que é uma empresa que tem tudo para crescer, expandir e continuar com o seu tipo de situação, a sinergia, pessoas e organização estão propensas a ter uma sobrevida maior do que as demais". (Entrevistado 4).

Dos conteúdos encontrados a respeito da definição de Entrincheiramento Organizacional, o significado mais presente no discurso dos entrevistados, foi o de um trabalhador acomodado, desmotivado, fracassado, sem perspectiva na vida, uma pessoa medrosa, que tem receios de arriscar a estabilidade que já atingiu na vida profissional.

O sentido da acomodação, bastante enfatizada para conceituar o trabalhador entrincheirado na organização, também esteve atrelado à falta de comprometimento com a mesma, não tendo sido identificados sinais de um vínculo afetivo saudável entre o trabalhador entrincheirado e a organização para a qual trabalha:

"O acomodado acho que é o medo mesmo que influencia, medo de mudança". (Entrevistado 5).

"O acomodado é desmotivado, não vê outra alternativa, não é criativo, quer cumprir só as obrigações, bater ponto só. Faz só o que é básico, está sem energia”. (Entrevistado 6).

"O acomodado tá totalmente desinteressado, ele é o oposto assim do outro (comprometido), ele fica na empresa por acomodação". (Entrevistado 7).

Assim, esse trabalhador, na visão dos gestores, é uma pessoa que deseja se manter na zona de conforto em função de uma visão materialista, por isso é precavido e cauteloso, tem foco na própria sobrevivência. Alguns discursos foram selecionados para ilustrar tais conteúdos:

"Na proporção que você estabelece uma rede de benefícios dentro de uma organização, esses benefícios terminam prendendo alguns trabalhadores, porque tem um plano de saúde, tem regras de conveniência que o atraem além do salário, porque o salário pode não ser dos melhores, mas você tem outras vantagens e benefícios que o envolvem". (Entrevistado 8).

A noção de Consentimento Organizacional também assumiu um sentido de acomodação, porém relacionado a um posicionamento pacífico, sem questionamentos ou críticas. O trabalhador que desenvolve esse tipo de vínculo, para os gestores das três organizações, é marcado pela submissão e pela subserviência, por alguém que cumpre automaticamente suas funções. Um dos gestores da organização 
municipal demarcou bem esse sentido: "O submisso não pensa, não questiona. Só balança a cabeça, não tem iniciativa, está sempre sendo comandado, não tem autonomia pra nada". (Entrevistado 9).

Além disso, surgiram nos discursos dos gestores das organizações públicas, definições de Consentimento que incluem as características pessoais, o sentimento de inferioridade, a falta de identidade, pessoa medrosa e calada, sem ânimo, irracional, limitada, passiva e interesseira. Nas palavras de um dos gestores: "é um puxa-saco, obedece porque não tem jeito". (Entrevistado 10).

Corroborando essas ideias, os gestores da organização privada relataram que um trabalhador com forte Consentimento Organizacional revela descompromisso com a organização, sendo um profissional medroso, sem perspectiva, e que exerce suas funções de maneira automática, sem análise e atribuição de significados.

No entanto, um dos gestores da organização federal, ao abordar o vínculo do tipo Consentimento, relatou que seguir normas da organização é algo que se faz necessário no contexto do trabalho:

"Normas e processos existem para serem seguidas. Não adianta você querer ir contra tudo que tem. Se não acredita na norma, aja para mudá-la. É importante seguir as normas principalmente em uma empresa pública que é recheada delas, algumas são desatualizadas e precisariam evoluir, mas elas existem e precisam ser seguidas". (Entrevistado 11).

No discurso de um dos gestores da organização privada, foi encontrado um sentido de compromisso mútuo, em que trabalhador e organização se comprometem com o cumprimento de normas e condições de trabalho, respectivamente:

"Toda organização possui normas, que são direitos e obrigações dos trabalhadores, uma relação de obediência, mas que vai fornecer um conjunto de regras a serem cumpridas só que, por contrapartida, a organização também precisa fornecer condições para o cumprimento de normas e para que o trabalhador desempenhe bem o seu papel. A partir do momento que você cria regras, você tem como consequência obrigações também. De forma bilateral, tanto da organização como do trabalhador". (Entrevistado 12).

Diferente do que expressaram em relação ao conjunto de ideias que definem o comprometimento, os gestores apresentam consenso em relação ao sentido negativo que entrincheiramento e consentimento carregam em si. Em ambos os casos, predominaram noções que não favorecem ao crescimento nem dos indivíduos nem das organizações, dificultando o alcance dos objetivos de ambas as partes.

\section{Considerações Finais}

Os dados obtidos com a exploração dos conceitos para os gestores forneceram evidências muito claras de que os três construtos se reportam a vínculos do trabalhador com a organização, efetivamente distintos. Essa diferenciação fica explícita tanto no conteúdo das denominações utilizadas para a descrição do trabalhador comprometido quanto na dimensão avaliativa subjacente ao uso de tais denominações. Claramente, nota-se que a noção de estar comprometido revela sempre um aspecto positivo tanto para o indivíduo quanto para a organização, indicando tratar-se de um vínculo propiciador de motivação e prazer perante a organização empregadora. Já o entrincheiramento pressupõe um aprisionamento do indivíduo à organização empregadora, um comportamento marcado pela acomodação, pois o empregado necessita se manter na organização em função dos benefícios que recebe e para garantir a própria sobrevivência. O consentimento, por sua vez, indica uma condição de subserviência para o trabalhador, condição que o submete a uma avaliação negativa enquanto pessoa e profissional. Os discursos dos gestores demonstraram que estes dois vínculos - Entrincheiramento e Consentimento - indicam adoecimento para ambas as partes - indivíduo e organização.

A análise do conceito de trabalhador comprometido revelou que os gestores esperam de suas equipes de trabalho indivíduos que estejam engajados e que revelem comprometimento com a organização aliado a uma expectativa de cumprimento de normas e de ordens, o que envolve, apesar da 
reduzida força, elementos do vínculo de obediência ou submissão em decorrência das relações de poder, da hierarquia já estabelecida na organização e da necessidade de adesão às regras que mantêm o funcionamento organizacional. Embora elementos do cumprimento das ordens e normas tenham aparecido no conceito de trabalhador comprometido, quando o mesmo gestor examina essas ideias associadas aos demais descritores de consentimento, há uma clara avaliação negativa a este tipo de comportamento. Os rótulos utilizados bem demonstram que um trabalhador passivo e simplesmente obediente não é desejável para a organização. Certa dose de adesão e identificação às normas, no entanto, é vista como positiva quando associada a características de comprometimento.

Como limitação do presente estudo, ressalta-se, aqui, que esta investigação não abordou no roteiro de entrevista as questões relacionadas aos contextos público e privado, bem como não enfatizou processos de liderança que podem exercer influência no desenvolvimento dos vínculos organizacionais que foram estudados. Por isso, sugere-se o desenvolvimento de novos trabalhos voltados para a análise e investigação de variáveis como tipo de segmento produtivo, e de liderança, como possíveis preditores ou elementos influenciadores de tais vínculos organizacionais.

O trabalho aqui apresentado é uma contribuição importante para o campo de estudo sobre comprometimento organizacional, especialmente para a definição deste construto e sua distinção entre novos vínculos que surgem na literatura nacional. Pois, o conceito de consentimento, como desenvolvido por Silva e Bastos (2010), parece abarcar outro tipo de vínculo do trabalhador com a sua organização não se configurando com comprometimento. Apesar disto, diferente do conceito de entrincheiramento, existem noções de consentimento (como identificação e adesão a normas) que são vistas como importantes em um trabalhador comprometido. Sugere-se o desenvolvimento de pesquisas que explorem o construto comprometimento focalizando, na mesma medida, as três dimensões - afetiva, normativa e de continuação - em comparação aos novos vínculos, aqui investigados, para obterem-se evidências mais distintivas e específicas entre as dimensões de Comprometimento e Entrincheiramento, e o Consentimento Organizacionais.

O presente estudo deve ensejar trabalhos que venham melhor delimitar o conceito de comprometimento organizacional, ao mesmo tempo em que possam equacionar de forma mais satisfatória a extensa discussão sobre as bases ou processos psicossociais que geram o comprometimento do trabalhador com a sua organização.

\section{Referências}

Abric, J. C. (1994). L'organisation interne des representations socials: systeme central et systeme peripherique. In C. Guimelli (Ed.), Structures et transformations des representations socials (pp 73-84). Lausanne: Delachaux et Niestlé.

Ajzen, I. (2001). Nature and operation of attitudes. Annual Review of Psychology, 52, 27-58. doi: 10.1146/annurev.psych.52.1.27

Allen, N. J., \& Meyer, J. P. (1996). Affective, continuance, and normative commitment to the organization: an examination of construct validity. Journal of Vocational Behavior, 49(3), 252276. doi: 10.1006/jvbe.1996.0043

Bastos, A. V. B., Brandão, M. G. A., \& Pinho, A. P. M. (1997). Comprometimento organizacional: uma análise do conceito expresso por servidores universitários no cotidiano de trabalho. Revista de Administração Contemporânea, 1(2), 97-120. doi: 10.1590/S1415-65551997000200006

Becker, H. S. (1960). Notes on the concept of commitment. The American Journal of Sociology, 66(1), 32-40. doi: $10.1086 / 222820$ 
Blau, G. J. (1985). The measurement and prediction of career commitment. Journal of Occupational Psychology, 58(4), 277-288. doi: 10.1111/j.2044-8325.1985.tb00201.x

Brito, A. P. M. P., \& Bastos, A. V. B. (2001). O schema de 'trabalhador comprometido' e gestão do comprometimento: um estudo entre gestores de uma organização petroquímica. Organizações \& Sociedade, 8(22), 177-193.

Buchanan, B. (1974). Building organizational commitment. The socialization of managers in work organizations. Administrative Science Quartely, 19(4), 533-546.

Carson, K. D., \& Bedeian, A. G. (1994). Career commitment: construction of a measure and examination of its psychometric properties. Journal of Vocational Behavior, 44(3), 237-262. doi: 10.1006/jvbe. 1994.1017

Carson, K. D., Carson, P. P., \& Bedeian, A. G. (1995). Development and construct of a career entrenchment measure. Journal of Occupational and Organizational Psychology, 68(4), 301-320. doi: 10.1111/j.2044-8325.1995.tb00589.x

Chusmir, L. H. (1982). Job commitment and the organizational woman. Academy of Management Review, 7(4), 595-602. doi: 10.5465/AMR.1982.4285252

Cunha, M. P., Rego, A., Cunha, R. C., \& Cabral-Cardoso, C. (2004). A ligação pessoa-organização. In M. P. Cunha, A. Rego, R. C. Cunha, \& C. Cabral-Cardoso (Orgs.), Manual de comportamento organizacional (pp 147-192). Editora RH: Lisboa, Portugal.

Dellagnelo, E., \& Silva, R. C. (2005). Análise de conteúdo e sua aplicação em pesquisa em administração. Rio de Janeiro: Editora FGV.

Hrebiniak, L. G., \& Alutto, J. A. (1972). Personal and role-related factors in the development of organizational commitment. Administrative Science Quarterly, 17(4), 555-573. doi: $10.2307 / 2393833$

Klein, H. J., Molloy, J. C., \& Cooper, J. T. (2009). Conceptual foundations: construct definitions and theoretical representations of workplace commitments. In H. J. Klein, T. E. Becker, \& J. P. Meyer (Eds.), Commitment in organizations: accumulated wisdom and new directions (pp. 3-36). Florence, KY: Routledge/Taylor and Francis Group.

Martins, G. A. de (2006). Estudo de caso - uma estratégia de pesquisa. São Paulo: Editora Atlas.

Mathieu, J. E., \& Zajac, D. M. (1990). A review and meta-analysis of the antecedents, correlates, and consequences of organizational commitment. Psychological Bulletin, 108(2), 171-194. doi: $10.1037 / / 0033-2909.108 .2 .171$

Meyer, J. P. (2009). Commitment in a changing world of work. In H. J. Klein, T. E. Becker, \& J. P. Meyer (Eds.), Commitment in organizations: accumulated wisdom and new directions (pp. 3768). Florence, KY: Routledge/Taylor and Francis Group.

Meyer, J. P., \& Allen, N. J. (1991). A three-component conceptualization of organizational commitment. Human Resource Management Review, 1(1), 61-89. doi: 10.1016/1053-4822(91)90011-Z

Meyer, J. P., \& Allen, N. J. (1997). Commitment in the workplace: theory, research and application. Thousand Oaks: Sage Publications.

Meyer, J. P., \& Herscovitch, L. (2001). Commitment in the workplace: toward a general model. Human Resource Management Review, 11(3), 299-326. doi: 10.1016/S1053-4822(00)00053-X

Moscon, D. H., Bastos, A. V. B., \& Souza, J. J. de (2012). É possível integrar, em um mesmo conceito, os vínculos afetivo e instrumental? O olhar de gestores sobre o comprometimento com a 
organização. Organizações \& Sociedade, 19(61), 357-373. doi: 10.1590/S198492302012000200010

Mowday, R. T., Porter, L. W., \& Steers, R. M. (1982). Employee-organization linkages - the psychology of commitment, absenteism, and turnover. New York: Academic Press.

O'Reilly C. A., \& Chatman, J. (1986). Organizational commitment and psychological attachment: the effects of compliance, identification, and internalization on prosocial behavior. Journal of Applied Psychological, 71(3), 492-499. doi: 10.1037/0021-9010.71.3.492

Pinho, A. P. M., \& Bastos, A. V. B. (2014). Vínculos do trabalhador com a organização: comprometimento, entrincheiramento e consentimento organizacionais. São Paulo: Hucitec.

Rodrigues, A. C. A., \& Bastos, A. V. B. (2011). Entrincheiramento organizacional: proposta de um novo vínculo indivíduo-organização. In J. C. Zanelli, N. Silva, \& S. R. Tolfo (Ed.), Processos psicossociais nas organizações e no trabalho (pp. 161-178). São Paulo: Casa do Psicólogo.

Scholl, R. W. (1981). Differentiating organizational commitment from expectancy as a motivating force. Academy of Management Review, 6(4), 589-599. doi: 10.5465/AMR.1981.4285698

Silva, E. C. da, \& Bastos, A. V. B. (2010). A escala de consentimento organizacional: construção e evidência de validade. Revista Psicologia, Organizações e Trabalho, 10(1), 7-22.

Vieira, M. M. F., \& Zouain, D. M. (2005). Pesquisa qualitativa em administração - Teoria e prática. Rio de Janeiro: FGV Editora.

Weber, M. (1971). Sociologia da burocracia. Rio de Janeiro: Zahar Ed.

Wiener, Y. (1982). Commitment in organizations: a normative view. Academy of Management Review, 7(3), 418-428. doi: 10.5465/AMR.1982.4285349

\title{
Dados dos Autores
}

\author{
Ana Paula Moreno Pinho \\ Av. Ademar de Barros, s/n., Pavilhão 04, Campus Univ. de Ondina, 40170-110, Salvador, BA, Brasil. E-mail: \\ anamorenopinho@gmail.com \\ Antonio Virgilio Bittencourt Bastos \\ Av. Ademar de Barros, s/n., Pavilhão 04, Campus Univ. de Ondina, 40170-110, Salvador, BA, Brasil. E-mail: \\ antoniovirgiliobastos@gmail.com \\ Diva Ester Okazaki Rowe \\ Av. Reitor Miguel Calmon, s/n., Vale do Canela, 40110-903, Salvador, BA, Brasil. E-mail: divarowe@gmail.com
}

